\title{
Estudio a las medidas cautelares innominadas, en vigencia del código general del proceso*
}

\author{
Diego Faubricio Cabrera Riaño** \\ Recibido: 5 de marzo de 2014 • Revisado: 10 de abril de 2014 \\ Aprobado: 20 de mayo de 2014.
}

\section{Resumen}

A lo largo de la historia legislativa colombiana, son múltiples las reformas que se han intentado integrar a la Rama Judicial para encauzar un modelo eficiente de justicia, donde se privilegie el acceso digno, aplicando procedimientos expeditos que permitan la pronta solución de conflictos sometidos a las diversas jurisdicciones y que sean acordes a los fines esenciales del Estado Social de Derecho, consagrado en la Constitución Política de 1991.

Es claro que las propuestas normativas para alcanzar la excelencia judicial, radican en la posibilidad de una solución efectiva al padecimiento permanente de la congestión en los despachos del país, como quiera que cada día el proceso en sí mismo, se torna complejo, pues aparece la dificultad de fallar los litigios o causas asignadas en el menor tiempo posible, sumado al número creciente de conflictos y disputas de intereses que por ausencia de la cultura en conciliación, le son asignados a los jueces para que decidan lo que en derecho corresponda.

La génesis de esta problemática le ha sido atribuida en materia civil, comercial, de familia y agraria, al modelo procesal imperante de los Decretos 1400 y 2019 de

" El presente artículo es producto de la investigación desarrollada por el autor, titulada: El impacto en el régimen procesal civil colombiano, con la vigencia del Código General del Proceso; para obtener el título de magister en Derecho Procesal en la Universidad Libre de Colombia.

** Abogado de la Corporación Universitaria Republicana, Bogotá, D.C., Colombia. Especialista en Derecho Público (Corporación Universitaria Republicana). Especialista en Derecho Procesal (Universidad Libre de Colombia). Monitor del Área Derecho Penal y Docente Corporación Universitaria Republicana. Magister en derecho procesal de la Universidad Libre. Correo electrónico: diegofacari@ gmail.com 
1970, por medio de los cuales se adoptó el Código de Procedimiento Civil, ya que contemplan trámites dispendiosos, que para hace 45 años pudieron se rápidos, pero que en el estado actual no se compadecen con las realidades del ritmo de vida de la sociedad. Así es como nace la Ley 1564 de 2012, que estatuye el Código General del Proceso y que se está a la expectativa de que su implementación en Colombia, sirva para acabar con la mora judicial; como quiera que trae novedosos elementos procesales, entre los que se encuentran la incursión de las tecnologías de la información, la oralidad, el cambio en los procedimientos imperantes y la adopción de trámites no previstos en pro de la efectiva función judicial.

El Código General del Proceso trae innovaciones procesales de diversas índole, entre las que se encuentra la variación que a las ya previstas medidas cautelares nominadas para ciertos procesos, se puedan peticionar y decretar cautelas innominadas, lo que implica no solo asegurar la efectividad de una futura sentencia estimatoria de las pretensiones, sino también el cese de ciertos actos distractores o perjudiciales para el demandante, que de antaño no podían ser suspendidos por la ausencia de facultades otorgadas por la ley a los jueces.

Surge de esta manera el problema a desarrollar, encaminado a establecer los presupuestos para que el juez de la causa en materia civil, comercial, de familia y agraria, pueda decretar la cautela innominada.

Palabras clave: cautela, nominada, innominada, apariencia de buen derecho, peligro en la demora, urgencia, decreto judicial, discrecionalidad.

\title{
STUdY OF UNNAMED INTERIM RELIEFS, IN FORCE UNDER THE GENERAL CODE OF PROCEDURE
}

\begin{abstract}
Throughout the legislative history Colombian, are numerous reforms that have tried the Judicial Branch to channel an efficient model of justice, where decent access to privilege, applying expeditious procedures for the prompt settlement of disputes under different jurisdictions and that are commensurate with the essential purposes of the rule of law, enshrined in the 1991 Constitution.

It is clear that policy proposals to achieve judicial excellence, lie in the possibility of an effective solution to the ongoing suffering of congestion in the offices of the
\end{abstract}


country, however it every day the process itself, complex it becomes, as it appears the difficulty fail litigation or cause assigned in the shortest time possible, plus the growing number of conflicts and disputes of interest that no culture of reconciliation, they are assigned to judges to decide what the law required.

The genesis of this problem has been attributed to him in civil, commercial, family and agricultural matters, the prevailing procedural model of Decrees 1400 and 2019 of 1970, by which it adopted the Code of Civil Procedure, as contemplated wasteful procedures, which for 45 years could rapids, but in the present state are incompatible with the realities of life rhythm of society. This is how the Law 1564 of 2012 enacts the General Code of Procedure and that is the expectation that its implementation in Colombia, serve to end the backlog, however it brings novel procedural elements born, among which find the incursion of information technology, orality, change to prevailing procedures and the adoption of procedures not provided in support of effective judicial function.

The General Code of Procedure brings procedural innovations from various kinds, including the variation of the coercive measures envisaged and nominees for certain processes, they can petition and decree caution is unnamed, implying not only ensure the effectiveness of future judgment by the claims, but also the removal of certain distracting or acts prejudicial to the plaintiff, who formerly could not be suspended by the absence of powers granted by law to judges.

Thus arises the problem to develop, aims to establish budgets for the trial judge in civil, commercial, family and agricultural matters, may order the innominate caution.

Keywords: Stealth, nominated, innominate, appearance of good right, danger in delay, urgency, writ, discretion.

\section{Estudo PARA AS MEDIDAS CAUTELARES INOMINADAS, EM VIGOR DO CÓDIGO GERAL DO PROCESSO.}

\section{Resumo}

Ao longo da história legislativa da Colômbia, são inumeráveis as reformas que se tem tentado integrar ao Poder Judiciário para canalizar um modelo eficiente de justiça, onde seja privilegiado o acesso digno, implementando procedimentos expeditos que permitam a pronta solução de disputas submetidas para as diversas 
jurisdições e que sejam acordes com as finalidades essenciais do Estado Social de Direito, consagrado na Constituição Política de 1991.

É claro que as propostas normativas para alcançar a excelência judicial, encontram-se na possibilidade de uma solução eficaz para o sofrimento contínuo do congestionamento nos escritórios do país, uma vez que cada dia o processo em si mesmo, torna-se complexo pois aparece a dificuldade de decidir os litígios ou causas atribuídas no menor tempo possível, acrescentado ao número em aumento de conflitos e disputas de interesses que pela ausência da cultura em conciliação, lhe são atribuídos aos juízes para que eles decidam aquilo que a lei exige.

A gênese desse problema foi atribuída em matéria civil, comercial, de família e questões agrícolas, ao modelo processual vigente dos Decretos 1.400 e 2.019 de 1970, por meio dos quais se adotou o Código de Procedimento Civil, devido a que contemplam procedimentos extravagantes, que há 45 anos poderiam ter sido rápidos, mas no estado atual são incompatíveis com as realidades do ritmo de vida da sociedade. É assim que nasce a Lei 1.564 de 2012, que aprova o Código Geral do Processo e que esta na expectativa da sua implementação na Colômbia, serva para acabar com o atraso judicial; o que quer que traga novos elementos processuais, entre os quais encontram-se a incursão das tecnologias da informação, a oralidade, a mudança nos procedimentos vigentes e a adoção de procedimentos não previstos em apoio à função jurisdicional efetiva.

O Código Geral do Processo traz inovações processuais de diversa índole, entre as quais se encontram a variação feita que às medidas cautelares já previstas e nomeadas para determinados processos, possam-se peticionar e decretar cautelas inominadas, o que abrange não apenas garantir a eficácia de uma futura sentença estimativa pelas pretensões, mas também a cessação de certos atos de distrações ou prejudiciais ao querelante, que outrora não podiam ser suspensos pela ausência dos poderes conferidos pela lei aos juízes.

Assim, surge o problema de desenvolver, visado a estabelecer os orçamentos para que o juiz de primeira instância em matéria civil, comercial, de família e questões agrícolas, possa ordenar a cautela inominada.

Palavras-chave: cautela, nomeada, inominada, aspecto do bom direito, perigo no atraso, urgência, mandado judicial, discricionalidade. 


\section{Introducción}

Los sistemas procesales actuales se debaten entre una serie de corrientes filosóficas que tienden a dar un concepto referente a la manera como debe impartirse la justicia, entre ellas están, por un lado, la del activismo, que clama por la reducción de los poderes del juez en la instrucción de los asuntos sometidos a su competencia y por la otra la del garantismo, que en oposición directa busca la posibilidad de dotar de mayores poderes y mecanismos al juzgador que debe dirimir los conflictos; vista esta situación las medidas cautelares innominadas o genéricas, como se han querido llamar por la doctrina, nacen como conquista del activismo judicial, en donde es el legislador quien faculta al órgano judicial con el poder cautelar típico y atípico según el litigio a resolver.

Para el caso colombiano, históricamente se venían manejando con el Código de Procedimiento Civil, medidas cautelares típicamente regladas, es decir, era el legislador quien en su potestad de configuración normativa enunciaba las cautelas que para determinados procesos y asuntos en conocimiento de los jurisdicentes debían ser decretadas, practicadas o levantadas; en ningún momento se le permitió a los directos conocedores de los conflictos de intereses y de las partes en especial, el determinar si la posibilidad de asegurar la futura satisfacción de la pretensión era suficiente con las herramientas que hasta entonces contaban, al regir el criterio de taxatividad.

\footnotetext{
En virtud de la cláusula general de competencia (Art. 150-2), el legislador está ampliamente facultado para regular y fijar en forma exclusiva los procedimientos judiciales, su acceso, etapas, características, formas, plazos y términos, al igual que deberes y cargas procesales, limitado tan solo por la razonabilidad y proporcionalidad de las medidas adoptadas, en cuanto estas se encuentren acordes con las garantías constitucionales de forma que permitan la realización material de los derechos sustanciales (Corte Constitucional Colombiana, C-279 de 2013, p. 3).
}

Es precisamente por esta circunstancia que nace del legislador con el Código General del Proceso, una posibilidad no otorgada expresamente por el ordenamiento procesal anterior a los jueces, como el adaptar la cautela a las necesidades reales del litigio, ya que no es solamente el decretar lo normado, sino lo que no se encuentra normado por lo complejo o diverso del tema a fin de precaver futuras sentencias de papel, imposibles de palpar en una realidad tangible. 


\section{Antecedentes al problema de investigación}

El proceso en sí mismo, lo conforma una serie de etapas que normativamente se encuentran regladas y cuyo fundamento real es la efectividad del derecho sustancial, a partir de la intervención judicial en la solución de conflictos sometidos a su competencia; como toda actuación estatal debe observar un conjunto de formalidades constitucional y legalmente definidas, que por su naturaleza son obligatorias, pero que se tornan lentas y en casos extremos eternas, ya sea por el número de asuntos sometidos al conocimiento de un mismo funcionario o por el despliegue procesal inoficioso surtido por las partes.

Como en su tiempo al denotar el padecimiento que modula toda actuación procesal, Carnelutti (2004) afirma: "así el proceso se arrastra en medio de una maraña de dificultades que retardan su marcha, agravan el costo y a menudo comprometen su resultado" (p. 29).

Nos encontramos en la disyuntiva que surge en el inicio del ejercicio de cualquier acción procesal, la cual estriba en determinar si la futura sentencia estimatoria de las pretensiones, podrá ser efectiva en el tiempo y consecuentemente los bienes o derechos inicialmente en contienda se conservarán de la misma manera al final de la actuación, lo que deviene en una carrera entre la efectividad de la justicia al declarar o proteger un derecho sustancial y el lento fenómeno temporal que entraña el proceso judicial.

Cómo se hace para conseguir que el oficio, cuando llegue el momento, encuentre en el patrimonio del deudor lo necesario, es decir o el bien debido o los bienes necesarios para procurar el bien debido.

La gravedad del problema está en que los remedios contra este peligro limitan naturalmente la libertad de la gestión del patrimonio del deudor con manifiesto daño social; los bienes secuestrados desmerecen así, como el peligro de medidas dirigidas a la revocación de las enajenaciones fraudulentas aleja a los adquirientes; estos quiere decir que se trata de remedios heroicos cuyas dosis deben administrarse con precaución (Carnelutti, 1944, p. 580).

Frente a la conservación y efectividad de la decisión de fondo, se ha erigido desde comienzos del derecho procesal, la institución de las medidas cautelares y cauciones, las cuales de manera general operan siempre que se den una serie de 
requisitos intrínsecos para otorgar cautelas procesales o extraprocesales (Alvarado, 2010), que ameriten la oportuna intervención del órgano judicial estatal, entre los que se encuentran el Fumus boni iuris, la urgencia y el Periculum in mora.

Unidos estos en forma sistemática, la doctrina se ha pronunciado para darle validez judicial. Chiovenda (como se citó en López, 2004) afirma: "el juez debe examinar si las circunstancias del daño dan serios motivos para temer el hecho dañoso y si el hecho es urgente y por lo mismo necesario" (p. 849).

Complementando, Fairen (como se citó en López, 2004) indica: “... y hacer un examen, evidentemente superficial, de la posibilidad del derecho. Son estos requisitos que la doctrina llama Pericumlum in mora y el Fumus boni iuris" (p. 850).

El Fumus boni iuris, o apariencia de buen derecho, entraña dos concepciones que es preciso tener presentes para entender su significado; por un lado se encuentra el mandato objetivo legal -abstracto, que indica la posibilidad de decretar medidas cautelares en ciertos procesos o actuaciones, observando las reglas prevista por el legislador, y por otra parte se encuentra el criterio subjetivo judicial- particular, del juzgador de turno, que una vez conoce del asunto en contienda debe entrar a sopesar el mandato legal, el valor probatorio de elementos allegados, la circunstancias especiales del caso y la petición del interesado en el proferimiento de una providencia cautelar, sin que se llegue a prejuzgar un asunto en el cual aún no se ha trabado la litis o después de haberlo hecho, no se ha dictado el fallo.

La apariencia de buen derecho, es un acto de razonamiento para llegar a la convicción, que se le pide que tenga el juez, al momento del decreto de una cautela, en el cual interviene un ejercicio de apreciación y los elementos propios de la ponderación.

El Periculum in mora y la urgencia, son conceptos estos íntimamente ligados, como quiera que el proceso que por naturaleza es lento, entraña en su seno el peligro en la demora, luego entonces existen ciertas situaciones que por apremiantes requieren una protección anticipada del juzgador para precaver específicamente que un daño previsible se materialice. La urgencia en sí es la base determinante para medir el peligro de la demora del proceso, pues el juzgador debe entrar a analizar si la intervención es requerida o por el contrario resiste el paso del tiempo.

El Periculum in mora que constituye la base de las medidas cautelares no es, pues, el peligro genérico del daño jurídico, el cual se puede en ciertos casos, obviar con la tutela ordinaria; sino que es específicamente el peligro del ulterior daño marginal 
que podría derivar del retardo de la providencia definitiva, inevitable a causa de la lentitud del procedimiento ordinario. Es la imposibilidad práctica de acelerar la emanación de la providencia definitiva, la que hace surgir el interés por la medida provisoria; es la mora de esta providencia definitiva, considerada en sí misma como posible causa de ulterior daño, la que se trata de hacer preventivamente inocua con una medida cautelar, que anticipe provisoriamente los efectos de la sentencia definitiva (Calamandrei, 1945, p. 42).

Visto lo anterior, es menester señalar que los precitados conceptos, operan indistintamente para las medidas cautelares nominadas e innominadas, por ello el problema a desarrollar radica en establecer lo siguiente: ¿¿cuáles son los presupuestos legales y fácticos, para que el juez en materia civil, comercial, familia y agraria, en vigencia del Código General del Proceso, pueda decretar la cautela innominada a petición de la parte interesada?

Para la solución al problema propuesto en el presente escrito, se realizará un análisis metódico, apoyado en diversas fuentes de consulta, partiendo de la norma de referencia en el Código General del Proceso, los presupuestos para el decreto de la medida cautelar innominada, la jurisprudencia de la Corte Constitucional Colombiana en materia cautelar y los pronunciamientos de la Superintendencia de Sociedades, concluyendo en el concepto objetivo del estado actual del tema.

\section{Referente normativo de la medida cautelar innominada}

El Código de Procedimiento Civil, estatuía las medidas cautelares en su libro cuarto, contemplando las de embargo y secuestro como los principales mecanismos para asegurar la futura satisfacción de la pretensión, en el evento que la misma llegase a prosperar en los procesos allí señalados; no obstante para ciertos asuntos como son los procesos ordinarios, en el acápite respectivo, estableció únicamente la medida cautelar nominada de inscripción de la demanda, donde según las reglas para su decreto y práctica, estaban íntimamente ligadas al principio de la taxatividad, según como puede observarse en el artículo 690 de la referida codificación, por lo anterior salta a la vista que en el ordenamiento procesal de los Decretos 1400 y 2019 de 1970, no fue incluido artículo o referente normativo que permitiera la 
facultad decisoria para que el juez pudiese llegar a decretar cautelas diversas a las ya autorizadas o expresamente indicadas.

Con el Código General del Proceso, nace normativamente para el ordenamiento procesal en materias civil, comercial, de familia, agraria y por remisión a otros ordenamientos, la cautela innominada o genérica, en los siguientes términos, según el literal c) del numeral primero del artículo 590, así:

Artículo 590. Medidas cautelares en procesos declarativos. En los procesos declarativos se aplicarán las siguientes reglas para solicitud, decreto, práctica, modificación, sustitución o revocatoria de las medidas cautelares:

1. Desde la presentación de la demanda, a petición del demandante, el juez podrá decretar las siguientes medidas cautelares:

[...] c) Cualquier otra medida que el juez encuentre razonable para la protección del derecho objeto del litigio, para impedir su infracción o evitar las consecuencias derivadas de la misma, prevenir daños, hacer cesar los que se hubieren causado o asegurar la efectividad de la pretensión.

Para decretar la medida cautelar el juez apreciará la legitimación o interés para actuar de las partes y la existencia de la amenaza o vulneración del derecho.

Asimismo, el juez tendrá en cuenta la apariencia de buen derecho, como también la necesidad, efectividad y proporcionalidad de la medida y, si lo estimare procedente, podrá decretar una menos gravosa o diferente de la solicitada. El juez establecerá su alcance, determinará su duración y podrá disponer de oficio o a petición de parte la modificación, sustitución o cese de la medida cautelar adoptada [...].

El citado artículo, es una viva muestra del avance legal en materia procesal que se ha venido teniendo en cuenta en el país, como quiera que el legislador acompasado con los devenires internacionales, inserta la facultad cautelar genérica para que el juez a petición de parte decrete medidas diversas a las ya previstas para procesos declarativos, dando alcance a diversos pronunciamientos y fallos constitucionales que en el mismo asunto se han construido, a fin de dar prioridad al del derecho sustancial, el acceso a la administración de justicia y el desarrollo del principio de eficacia que debe estar presente en todas las determinaciones judiciales; así es como la Corte Constitucional (2004) ha indicado: 
Las medidas cautelares son instrumentos procesales para asegurar la efectividad de los derechos judicialmente declarados, y han sido consideradas como un componente del derecho de acceso a la Administración de Justicia, en virtud a que tal derecho comprende no solo la pretensión de obtener un pronunciamiento judicial en torno a los derechos, sino la materialización de las medidas que los hagan efectivo (Sentencia C- 039).

\section{Presupuestos para el decreto judicial, de la medida cautelar innominada}

Por principio general las medidas cautelares, como en la mayoría de actos procesales, son dispositivas, es decir está en la parte que desea tener la protección o servicio de justicia, la proposición de lo que quiere que en derecho le sea concedido y su consecuente impulso; la doctrina ha establecido que las mismas son rogadas y accesorias, por ende la petición ha de ser formulada al juez para que las conceda, previo estudio de los requisitos fácticos y jurídicos, corriendo ellas cuando prosperen la suerte del proceso. Es por lo anterior, que las medidas cautelares innominadas o genéricas contienen las precitadas características, en ellas impera por encima de las medidas cautelares nominadas el acontecer dispositivo de parte, ya que está en el sujeto procesal proponente el acoplar los hechos a los mecanismos procesales que posibiliten su decreto y que sean lo suficientemente razonados y razonables, en pro de una estimación favorable por vía judicial.

Para que la medida cautelar innominada, pueda ser decretara y sea procedente, debe cumplir con los siguientes supuestos normativos a tener en cuenta:

Momento de proposición. Enmarcado este como la oportunidad en el tiempo para presentar la petición de parte, ante el juez de la causa y lograr su decreto judicial, en el artículo 590 del Código General del Proceso, se encuentra determinado que desde la presentación de la demanda por petición misma del demandante puede el juez decretar la cautela innominada, lo que indica que bajo esta figura, el actor sin siquiera haberse trabado la litis, está facultado a deprecar del juzgador las medidas conservativas que a bien tenga para la protección efectiva del derecho sustancial que eventualmente deberá de ventilarse y decidirse en el proceso.

No obstante lo anterior, también es claro que el ámbito de proposición temporal no se circunscribe solamente a la fase inicial del proceso con el acto de introducción, también es notorio que si en el devenir de la actuación procesal se encuentra 
plenamente demostrado la necesidad de la medida cautelar innominada, el actor acudiendo al principio dispositivo, puede promover su decreto con los argumentos concretos y las herramientas probatorias del caso; aunque la norma no prevé momentos temporales de proposición de la medida, al establecer que desde la presentación de la demanda puede peticionarse, deja la puerta abierta para que en el transcurso de las actuaciones posteriores donde se desarrolla el litigio, encuentre fundamentos para su decreto:

3.1. El demandante pude solicitar la medida cautelar con posterioridad, cuando se ha trabado la relación jurídico procesal, consideramos que sí, inclusive teniendo presente que el demandado ha contestado la demanda, en una forma que le da apariencia más fundada al derecho que se pretende o lo contrario (Parra, 2013, p. 318).

Quedan en el tintero las siguientes eventualidades, que han de ser resueltas en trabajos posteriores, pero que ameritan pronunciamiento por el desarrollo del tema, en primera lugar qué ocurre cuando desde la presentación de la demanda haya sido propuesta la medida cautelar innominada y no fuese decretada en un primer momento por el juez, pero que en el devenir de las actuaciones procesales después de trabada la litis, aparezcan pruebas suficientes que ameriten su decreto, será posible que el juez en un segundo estudio nuevamente motivado por petición de parte puede entrar a rectificar lo ya trasegado y reversar la decisión inicial; en segundo lugar establecer cuando la sentencia es apelada y por remisión al numeral primero del artículo 323 del Código General del Proceso, si el juez de primera instancia al conservar la competencia para conocer de medidas cautelares, le es posible en este momento procesal decretar la cautela genérica, solicitada por la parte.

Objeto de la medida cautelar innominada. Aunque genéricamente las medidas cautelares han tenido por objeto la protección del derecho sustancial y la efectividad de la sentencia estimatoria de las pretensiones cuando la misma sea emitida, específicamente para la cautela innominada el Código General del Proceso, enmarca que este obedece a: 1) que el juez encuentre otra medida razonable para la protección del derecho objeto del litigio, otorgando a más de las tradicionales cautelas, la posibilidad de innovar en los mecanismos de protección que permitan por medio de un juicio de valor establecer cuál será el más idóneo, en virtud de un espectro de configuración tutelar amplio y que ha de ser debidamente sustentado; 2) impedir su infracción o evitar las consecuencias derivadas de la misma, enunciación con tinte 
constitucional, que es similar a los mecanismos de protección que se encuentran en la acción de tutela, para el caso en estudio ya no solamente están en contienda la vulneración de derechos fundamentales, sino la protección directa de derechos de cualquier orden y que se encuentren íntimamente relacionados con el objeto del litigio; 3) prevenir daños, hacer o cesar los que se hubieren causado, igualmente con fundamento constitucional similar a las acciones de grupo o populares, el poder cautelar del juez viene enmarcado en la facultad protectora hacia el potencial o permanente daño que afecte el derecho en contienda y que su declaratoria en el tiempo lo haría ilusorio; 4) finalmente asegurar la efectividad de la pretensión.

Los anteriores enunciados normativos, obedecen a los propósitos queridos y desarrollados en materia general para la efectividad de las medidas cautelares innominadas, salvo el último donde se vislumbra que el legislador, más que permitir la realización de la pretensión, lo que puede llegar a insertar es la posibilidad procesal del decreto de una medida de anticipación material del fallo estimatorio, que en cierta medida constituiría una vulneración directa a los derechos de contradicción y defensa del demandado; algunos autores han querido para esta clase de situaciones, el precaver la transgresión de derechos ciertos de la parte pasiva, con propuestas tales como la realización de una audiencia previa que permita atemperar un posible perjuicio.

De ahí entonces que aquí se postule que todo anticipo de sentencia debe gozar siempre de necesaria e imprescindible audiencia previa pues nada molesta al efecto y no se vulnera la garantía máxima representada por el irrestricto mantenimiento del método del debate entre sujetos igualados jurídicamente por la propia imparcialidad del juzgador. En buen romance, esto significa algo así como idear trámites harto breves o, más simplemente ocurrir a la tradicional figura del amparo, comprensiva de todos los casos que actualmente se tratan por vías autosatisfactivas (Alvarado, 2013, p. 865).

Es sin lugar a dudas el concepto de garantizar la efectividad de la pretensión, bastante complejo para el juez a quien se le haga la proposición de su decreto, en razón a que puede incurrir en un prejuzgamiento del asunto, la limitación de derechos ciertos o la terminación anticipada del pleito por la concesión prematura de las peticiones queridas en la demanda; se trata pues de establecer que la medida cautelar innominada en este tema sea una herramienta que viabilice el aseguramiento 
de la pretensión y no se convierta en la eventual forma de lograr deseo procesal de la parte a costa de vulneración de los derechos del demandando, por ausencia de contradicción. Así, Alvarado (2013) afirma: “cuando esto se hizo el legislador no advirtió que nada cautelaba sino que bien por el contrario, anticipaba el contenido de una sentencia declarativa o de condena que, además, en algunos casos no llega a dictarse jamás" (p. 838).

El criterio de instrumentalidad que entraña la medida cautelar innominada, hace que todas las decisiones en torno a ella proferidas por el juez previa petición de parte, estarán sometidas a los resultados finales del proceso, lo que permite colegir que en los eventos en los cuales de manera inicial se haya dispuesto el poder cautelar para garantizar la efectividad de la pretensión o la anticipación material del fallo, con la toma de decisión que resuelva el litigio, si la misma no es estimatoria, puede ordenar inmediatamente el cese de la cautela.

Legitimación y apariencia de buen derecho. En la enunciación normativa que consagra el literal C, del artículo 590 del Código General del Proceso, está que el juez para el decreto de la medida cautelar innominada deberá apreciar la legitimación o interés para actuar de las partes, es decir como no ocurría en las medidas cautelares nominadas, donde la facultad para solicitar y decretarlas venía por mandato mismo del legislador previa verificación de requisitos formales, en la cautela genérica o atípica, si es preciso que el juez de conocimiento, realice junto al estudio previo de adminisibilidad de la demanda, el de la legitimación en la causa para la solicitud. La razón de ello radica en que al ser la cautela innominada, un mecanismo novedoso en la legislación procesal colombiana, obliga a que el juez sea mucho más cuidadoso en el decreto judicial, debido a que no se trata solamente de salvaguardar anticipadamente los intereses de la parte demandante, sino que conlleva en sí, un cierto toque de perjuicio y afectación a los derechos o patrimonio del demandado.

[...] Si en todos los casos, para decretar o negar la cautela el juez pudiese cuestionar la legitimación de las partes o la existencia o vulneración del derecho, el nuevo Código sería regresivo en cuanto al poder cautelar de las partes, e implicaría un incremento desmedido de los poderes del juez, quien estaría así facultado para denegar la medida típica de inscripción de la demanda con el argumento de que el demandante o el demandado carecen de legitimación, o emitiendo un juicio antelado sobre la existencia del derecho o acerca de su vulneración; lo cual parece 
razonable para la cautela atípica, más no para la medida tradicional de inscripción de la demanda (Villamil, 2012, p. 178).

Es claro igualmente, que el estudio inicial por parte del juez de la legitimación o interés no es absoluto, como quiera que el demandado al momento de contestar la demanda pueda proponer la ilegitimación en la causa por activa y al prosperar esta, derribaría uno de los pilares en el decreto de la cautela innominada.

Para apreciar la correcta legitimación o interés, ha de tenerse en cuenta la apariencia de buen derecho, conceptualizada ya en precedencia, indica que se debe determinar por medio de las pruebas que sean arrimadas con la demanda y el estudios de los hechos, la posible verosimilitud del derecho que se quiere, sea reconocido.

Además tendrá en cuenta la apariencia de buen derecho (Fumus boni juris), es decir, siendo el derecho del demandante más probable que el del demandado. La verosimilitud depende del contenido del derecho material de la "alegación”, el cual debe ser identificado con base en la tutela pretendida y en los fundamentos invocados para su obtención. De modo que el derecho a obtener esta participación, no se contenta con la mera constatación de la verosimilitud, como la mera "alegación" sin contenido, sino que la verosimilitud solamente puede ser comprendida a partir de las diferentes necesidades del derecho material (Parra, 2013, p. 312).

En concreto el juzgador a quien le sea propuesta la medida cautelar innominada, se encuentra en la obligación de realizar un estudio más detallado y concienzudo de los medios de prueba inicialmente presentados, debido a que no bastará la mera afirmación del actor que aunque se encuentre fundada en hechos aparentemente verdaderos, a los mismos se les debe acompañar de elementos que permitan por medio de una inferencia lógica, el llegar a la convicción necesaria para que el juez pueda tomar la decisión o pro del decreto del amparo solicitado.

Nos encontramos en un cambio profundo para la mentalidad de los abogados que hagan uso del Código General del Proceso, ya que cuando quieran proponer la medida cautelar innominada, no bastará con la mera afirmación frente lo relatado en acápite fáctico del grueso de la demanda, sino que además de ello tendrán que adosar las pruebas y las consideraciones de orden legal en la solicitud de amparo, requiriendo así una carga argumentativa y probatoria cualificadas de mayor calado; la exposición de los hechos, la relación de normas sustanciales y procesales, así 
como el manejo de los elementos indicativos del derecho, han de ser expuestos de manera clara, concisa y fundada, con el fin de darle al juez un argumentado grado de convencimiento.

El peligro en la demora y la urgencia. Por la ya marcada experiencia de los procesos llevados por el hilo del Código de Procedimiento Civil, es claro que para el trámite ordinario-declarativo, la duración del mismo estaba estimada en promedio de cinco a ocho años surtiendo la totalidad de la instancias, fuera del recurso extraordinario de casación; crítico a este padecimiento temporal que debía soportar el demandante por el lento modelo de justicia imperante, el Código General del Proceso trae consigo la promesa de celeridad en los trámites, sin embargo la misma normatividad es consciente que no están de más los paros judiciales extraordinarios, los días de vacancia por la ley otorgados donde la totalidad de los despacho judiciales cierran sus puertas, las actuaciones procesales de algunos profesionales del derecho especializados en dilatar las decisiones y todas las contingencias que puedan hacer eterno un proceso.

Asimismo, existen derechos que por lo fugaces de sus contextos pueden perecer en el tiempo y que de no ser protegidos en el momento adecuado, no estarán presentes o será el grado de vulneración tan flagrante que ya la sentencia estimatoria de las pretensiones no logrará el cometido inicial al que motivo la proposición de la acción procesal.

Bajo estas dos figuras es como el literal C, del artículo 590 del Código General del Proceso, con los enunciados normativos de existencia de amenaza o vulneración del derecho, hacen referencia a la figura del peligro en la demora y la urgencia, que son situaciones fácticas que se presentan, pero que legalmente le corresponde al juez el contemplarlos. Andrea (como se citó en Parra, 2013) indica que las resoluciones de urgencia están caracterizadas por una doble atipicidad: atípico es tanto el Periculum in mora como el contenido de la resolución, le sigue el que tales resoluciones puedan ser pedidas (en tutela de cualquier derecho) para neutralizar el Periculum in mora, siempre que aquel llegue a los extremos del perjuicio inminente e irreparable; en cuanto al contenido de la resolución, este debe ser individualizado por el juez "según las circunstancias" con base al solo criterio de la idoneidad "para asegurar provisionalmente los efectos de la futura decisión sobre el fondo”.

La duración y variación de la medida cautelar innominada. Como principio general la medida cautelar innominada, al igual que su similar nominada es accesoria al proceso en sí. Rangel (1989) afirma: "la duración de las medidas innominadas, 
como la de cualquier otro tipo de medidas cautelares, es provisoria. Su función se agota con el pronunciamiento de mérito que decide el asunto que dio origen a la medida" (p. 107).

Lo que las diferencia sustancialmente la una de la otra es su duración; para la cautela típica es inmutable y permanente, salvo petición de levantamiento por quien la soporta previa caución judicial, para la genérica el Código General del Proceso, en primer término le otorga al juez la facultad de establecer, basándose en las reglas de la sana crítica el posible grado de afectación o impacto que pudiese llegar a tener frente al demandado, así es como le permite atemperar la solicitud inicial de parte y en el evento que la encuentre desproporcionada o inútil, pueda decretar una menos gravosa o diferente a la deprecada. Esta situación se presentará conforme a los diversos casos que lleguen a conocimiento del juzgador, la máxima de modificación y merma no son absolutas, dependiendo de los hechos, las pretensiones y estudio indiciario que se haga a partir de las pruebas inicialmente allegadas, la petición cautelar se mantendrá incólume o será adaptada satisfactoriamente al devenir procesal.

Aunado a lo anterior, la duración de la cautela innominada es relativa, empezando porque desde el mismo decreto el juez se encuentra en la obligación legal de establecer su caducidad, teniendo como referente la clase de protección concedida y las condiciones de cada proceso, para su persistencia en el tiempo. Así, es como la misma normatividad procesal, le otorga igualmente la facultad de decretar a petición de parte o de oficio, la modificación, terminación o sustitución de la cautela ya decretada, porque puede ocurrir que inicialmente se impuso una medida fundamentada en petición inserta en la demanda, pero posterior a ello después de haberse trabado la litis, con las pruebas allegadas por el demandando y su consecuente despliegue procesal se avizora que debe ser cambiada por una más efectiva, cesarla porque no reviste ninguna practicidad para el proceso o reemplazarla por una más benévola o severa.

\section{Pronunciamientos de la Superintendencia de Sociedades, respecto de las medidas cautelares innominadas}

En Colombia no han sido muchas instancias judiciales que hayan desarrollado el concepto de medidas cautelares innominadas, debido a que es lógico que en materia jurisprudencial por parte de la Corte Suprema de Justicia o de los Tribunales 
aún sean escasos, por no decir inexistentes pronunciamientos al respecto, pues los procesos en vigencia del Código General del Proceso, están en su fase de implementación a nivel nacional, se estima que se comience a producir jurisprudencia en aproximadamente dos años, siempre que el cronograma de implementación de la norma se cumpla en los tiempos previstos.

En donde sí se ha avanzado en la petición, decreto y práctica de las medidas cautelares innominadas, es en los procesos llevados ante a Superintendencia de Sociedades, allí se tiene desde el año 2012 como tema procesal decisorio la manera de aplicación del artículo 590 del Código General del Proceso, en los diversos asuntos llevados a esta instancia; pronunciamientos los cuales servirán de referente cualificado para cuando comiencen a requerirse en los diversos despachos del país, en materia civil, comercial, de familia y agraria.

Entrando en el detalle de la actuación surtida por la Superintendencia de Sociedades, en materia de medidas cautelares innominadas, encontramos que:

Para el mes de diciembre de 2012, en el proceso verbal sumario, referente al asunto del artículo 24 del Código General del Proceso, donde figuraban como parte la Cámara de Comercio de Barranquilla contra Carcos Mantenimiento de Equipos S. A. S., y otros; la apoderada de la parte demandante solicita que se decrete la medida cautelar innominada, consistente en la "suspensión provisional de las matriculas mercantiles de las sociedades demandadas", basándose en la necesidad de "proteger la transparencia del proceso electoral de la Cámara de Comercio, programada para el 20 de diciembre de 2012 e impedir que esas sociedades constituidas con fraude a la ley sigan registrando actuaciones encaminadas a legitimar y borrar las irregularidades cometidas en su constitución”. Aperturada la actuación procesal el superintendente delegado para asuntos mercantiles, por medio del Auto número 801- 01366, datado el 10 de diciembre de 2012, se pronunció a la petición de la parte solicitante, tomando fundamento en el artículo 590 del Código General del Proceso y realizó un estudio pormenorizado de los requisitos para la concesión final de la medida peticionada.

En un primer momento de análisis denominó "probabilidades del éxito de las pretensiones formuladas en la demanda", donde la apariencia de buen derecho la basó citando a J. Garnica Martín (2008): "la carga de acreditar prima facie, esto es, de forma provisional e indiciaria, que la pretensión [...] presenta visos de poder prosperar; [es preciso establecer] una probabilidad cualificada de éxito de la 
pretensión cautelar que se pretende cautelar" (p. 580). En la misma providencia la Superintendencia de Sociedades (2012) por medio de su delegado, indicó:

[...] Al tratarse de una valoración previa de las pruebas disponibles cuando se solicita la medida cautelar, es perfectamente factible que, al momento de dictar sentencia, el juez llegue a una conclusión diferente de la expresada en el auto de medidas cautelares. En efecto, durante el curso del proceso pueden surgir elementos de juicio que le resten fuerza a los argumentos empleados por el juez para haber aceptado o rechazado la medida (Auto número 801- 01366).

Realizando un recuento cronológico del problema planteado por la situación fáctica presentada, depuró el concepto de sociedades por acciones simplificadas, examinó detalladamente el caudal probatorio e hizo una síntesis de indicios, que agrupó en enunciados perfectamente desarrollados entre los que se destacan, exámenes a la constitución de la sociedad, simetría del capital social, número de empleados, variación en los cargos de representación legal en un periodo de tiempo, uniformidad en los formatos para constitución, composición de la razón social de las sociedades demandadas, el parentesco entre los representantes de las compañías, similitud de dirección y teléfonos registrados, expedición masiva de certificados de cumplimiento de las obligaciones y votos de las sociedades demandada en las elecciones de la Junta Directiva en las elecciones de la Cámara de Comercio 2012-2014. Lo anterior hizo que la apariencia de buen derecho fuese calificada por vía indiciaria, con una probabilidad de éxito suficientemente alta en las pretensiones.

Acto seguido la Superintendencia de Sociedades, por medio de su delegado, analizó lo que denominó "Interés para actuar", donde efectuando una valoración de la naturaleza jurídica de las cámaras de comercio y las facultades legales, determinó que existe razón suficiente de parte para promover la acción por el representante legal de las Cámaras de Comercio, al ser un garante del proceso electoral en la elección de sus directores. El siguiente punto de análisis lo enmarcó en la "existencia de una amenaza inminente y la necesidad de la medida”, que lo hizo consistir en que como el registro mercantil es un instrumento de publicidad, al estarse en la indagación de una posible fraude en las elecciones de la composición de la junta directiva de la Cámara de Comercio de Barranquilla, se debe preservar el orden público de la entidad encargada de llevar el aludido registro. 
Otro de los factores estudiados fue la "efectividad y proporcionalidad de la medida", donde en este momento la Superintendencia de Sociedades haciendo uso de la facultad para decretar una medida cautelar diferente a la solicitada, indicó que pese a la petición de suspensión de las matriculas mercantiles de las compañías demandadas, existían otras medidas más proporcionales y eficaces variando las mismas, en la suspensión de la afiliación de las sociedades, la remoción de la sociedades demandadas de la lista de comerciantes habilitados para votar y la suspensión de las designaciones y posesión de los sujetos elegidos anteriormente. Finalmente la Superintendencia de Sociedades señala la caución con el objeto de garantizar los posibles perjuicios que se llegasen a presentar con la materialización de las medidas cautelares decretadas, con un criterio de ponderación en las reglas contenidas en el artículo 590 del Código General del Proceso.

Otra actuación que vale la pena resaltar por parte de la Superintendencia de Sociedades, en el tema de medidas cautelares innominadas, es la adoptada en el Auto número 801-001488 del 1 de febrero de 2013, siendo partes Refricenter Internacional Trade Zona Libre S. A., contra Refricenter Group S. A. S., y otros. Donde el asunto en debate versó en la solicitud inicial del demandante de que se ordenara rescindir los votos emitidos por el señor Jorge Antonio Restrepo "durante la reunión extraordinaria de la asamblea general de accionistas de Refricenter Group S. A. S.”, en asocio con la pretensión inicial, fue solicitada por parte de la demandante las medidas cautelares innominadas "orientadas a dejar en suspenso las decisiones de la asamblea de accionistas de Refricenter Group S. A. S., adoptadas el 15 de diciembre de 2012, así como los contratos celebrados por Carlos Alberto Urquijo Illera, en su calidad de representante legal de la compañía".

Para el estudio de la petición cautelar genérica, la Superintendencia de Sociedades, por medio de su delegado, basó sus argumentos en tres puntos a tratar, en primer término en las "probabilidades del éxito de las pretensiones formuladas en la demanda”, donde por medio de un estudio sistemático de las pruebas aportadas, las normas alegadas y los indicios que aparecían estimó una alta probabilidad de éxito en la demanda; por otra parte, hizo énfasis en lo que se llamó "el interés económico del demandante”, para fundamentar el interés, la legitimación de parte y la necesidad que le asiste a la sociedad promotora de la acción, por el grado de afectación económica que puede llegar a presentarse si no se adopta la medida a tiempo; en un último escenario de estudio fue fijado el monto de la caución que ha de cubrir el demandante para la materialización de la medida innominada. 
Igual como aconteció en la providencia del año 2012, la Superintendencia varió la petición inicial de medida cautelar innominada, no solamente concediéndola, sino adicionándola con la inscripción de la demanda en el registro mercantil, llevado ante la Cámara de Comercio de Barranquilla.

Finalmente obsérvese el pronunciamiento contenido en el Auto número 801016441 del 3 de octubre de 2013, dentro del proceso verbal sumario llevado ante la Superintendencia de Sociedades, siendo partes RCN Televisión S. A., contra Media Consulting Group S. A. S., en donde se planteó que la demandada por intermedio de su representante, realizó un acto de defraudación de los intereses económicos de los acreedores, por habérsele tenido a la expectativa de garantizar su crédito con un bien, al cual nunca se le impuso gravamen alguno y posteriormente fue ocultado y dado en donación; por ello se solicita que en el respectivo folio de matrícula inmobiliaria se inscriba la demanda, como medida cautelar nominada.

Entrando el despacho a analizar el asunto en cuestión, nuevamente hace un cálculo de "las probabilidades del éxito de las pretensiones formuladas en la demanda", encontrando en ese minucioso estudio que la apariencia de buen derecho lo soportan los actos plasmados en los estados financieros de la demandada, los soportes contables aportados por la demandante, que cuando se realizó la contratación se contaba con un activo fijo o bien inmueble que daba una garantía suficiente, pero que posteriormente por un acto de donación salió del patrimonio de la sociedad demandante, lo que hizo que no se contara con la prenda general de los acreedores. Sumado a lo anterior, pese que la compañía demandante había iniciado un proceso de cobro ante la justicia ordinaria, no pudo ser materializada medida cautelar alguna, porque ya el bien no se encontraba en cabeza de la demanda. Para acreditar el interés se basó en el interés económico legítimo y fijó los límites del valor a caucionar. La parte resolutiva de la providencia tiene un notorio cambio, pues varía la medida solicitada inicialmente porque a criterio del Despacho, debe no solamente asegurarse la pretensión, sino que guarda una relación directa con los efectos nocivos que al parecer se derivaron de la donación, por ello decreta de manera innominada la suspensión de los efectos de la donación efectuada.

\section{Conclusiones}

Las medidas cautelares innominadas son una de las novedades importantes del activismo judicial en el Código General del Proceso, que trata de dotarlo de 
mecanismos idóneos en el cometido de la descongestión judicial y la efectividad material de las sentencias.

Para el decreto y práctica de la medida cautelar innominada, se requiere petición de la parte demandante a la luz del artículo 590 del Código General del Proceso, pero una vez realizada la misma, se activa el poder discrecional del juzgador que conoce del asunto, pues la norma lo dota de herramientas para establecer su temporalidad y variar la petición inicial.

Para el abogado proponente de una medida cautelar innominada, se ha incrementado la carga argumentativa en su solicitud, como quiera que en ella debe contemplar tanto los fundamentos fácticos y legales que tiene a la mano, como el valor probatorio de los elementos que desee aportar; se trata de un juicio inicial de ponderación del profesional derecho, que valiéndose de la razón ha de pretender pensar de la manera como posteriormente el juez lo hará, siendo la prueba indiciaria el mecanismo apto en la construcción de los argumentos.

La medida cautelar innominada debe ser minuciosamente estudiada por el juez, debido a que con fundamento en el poder discrecional que tiene para adoptar un decisión, puede incurrir en prejuzgamiento o una solución anticipada del conflicto, sin siquiera haberse sometido el asunto a contradicción.

Los referentes próximos que da la Superintendencia de Sociedades en las decisiones donde se mencionan las medidas cautelares innominadas, pueden servir inicialmente como herramientas de consulta, para que los funcionarios que deban estudiarlas y decretarlas tengan una idea de la actuación a surtir.

\section{Referencias}

Alvarado, A. (2010). Lecciones de Derecho Procesal Civil. Asunción: Editorial La Ley.

Álvaro, A. (2013). Ponencia, el procedimiento cautelar y la solución urgente y anticipada de una pretensión. Medellín: XXXIV Congreso Colombiano de Derecho Procesal.

Calamandrei, P. (1945). Providencias Cautelares. Buenos Aires: Editorial Bibliográfica Argentina.

Carnelutti, F. (2004). Cómo se hace un proceso. Bogotá, D.C.: Editorial Temis.

Carnelutti, F. (1944). Sistema de Derecho Procesal Civil, Tomo II Composición del Proceso. Buenos Aires: Editorial Hispano Americana.

López, H. (2004). Procedimiento Civil, parte especial. Bogotá D.C.: Dupre Editorios.

Parra, J. (2013). Ponencia, medidas cautelares innominadas. Medellín: XXXIV Congreso

Colombiano de Derecho Procesal. 
Rosemberg, A. (1989). Ponencia, medidas cautelares innominadas. Bogotá D.C.: Revista del Instituto Colombiano de Derecho Procesal. Recuperado de www.icdp.org.co/revista/ usuarios/edicionesAnteriores/1989.php

Villamil, E. (2012). Ponencia, algunos apuntes acerca de las cautelas en el Código General del Proceso. Bogotá D.C.: XXXIII Congreso Colombiano de Derecho Procesal.

Sentencia C-039 de 2004, (Corte Constitucional). Recuperado de http://www.corteconstitucional.gov.co/relatoria/2004/C-039-04.htm

Sentencia C-279 de 2013, (Corte Constitucional). Recuperado de http://www.corteconstitucional.gov.co/relatoria/2013/C-279-13.htm

Auto número 801-017366 del 10 de diciembre de 2012, (Superintendencia de Sociedades). Jurisprudencia Societaria 2014.

Auto número 801-001488 del 1 de febrero de 2013, (Superintendencia de Sociedades). Jurisprudencia Societaria 2014.

Auto número 801-016441 del 3 de octubre de 2013, (Superintendencia de Sociedades). Jurisprudencia Societaria 2014. 